\title{
AL-MIRBAD: UN FESTIVAL DE POESÍA EN IRAQ
}

Por

INGRID BEJARANO ESCANILLA

"Por nuestro pasado cantamos,
por nuestro futuro lanzamos la palabra».

Bajo este lema fue inaugurado en Bagdad (Iraq) el pasado 24 de noviembre de 1987 el VIII Festival de Poesía.

Este Festival, que recibe el nombre de al-Mírbad (1), se viene celebrando desde hace ocho años bajo los auspicios del Ministerio de Cultura e Información de la República del Iraq. Con motivo de su celebración fueron invitados este año más de mil quinientos participantes entre poetas, novelistas, críticos literarios - en su mayoría árabes - y orientalistas de diversos países de todo el Mundo. La República de Iraq, presidida por el Presidente Șaddām Husayn, decidió que, a pesar de la guerra, se celebrara un año más el Festival, poniéndose así de manifiesto el permamente interés de este país por la cultura y la firme decisión de potenciar y proteger su desarrollo, garantizando su normal continuidad no obstante el grave conflicto que supone una guerra que, desgraciadamente, cuenta los mismos años que el Festival.

El tema central del VIII Mirbad fue La poesía árabe en los finales del siglo $X X(2)$. Este VIII Mirbad quedó desdoblado, como en años anteriores, en una serie de sesiones de recitación poética y en otra serie de sesiones de debate y crítica literaria. Estas últimas fueron presididas por el director general de Asuntos Culturales del Ministerio de Cultura e Información de Iraq, Dr. Muhsin al-

(1) al-Mirbad era una especie de ferla ganadera celebrada antiguamente en la ciudad de Basora, en la que se daba especial importancia a las recitaciones poéticas.

(2) El tema del VII Mirbad fue "El lugar de la poesía en la cultura árabe contemporánea". 
Mūsāwì y en ellas participaron además de un gran número de críticos iraquíes, entre ellos Faḍl Īāmir, "Inād Gazwãn, Tarrād al-Kubaysī y Māŷid al-Samarrā'ti, otros muchos de los demás países árabes, entre los que cabe destacar a ${ }^{c} / z z$

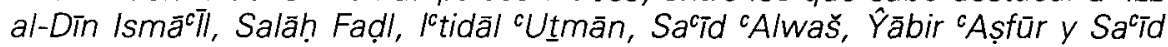
Taršuna. Los temas principales sometidos a debate fueron: la situación actual de la poesía árabe; la poesía árabe contemporánea; poesía y tradición. y la poesía de guerra (3). Se trató de dar una valoración estética de los poemas y de analizar su finalidad y su función como un "arma», utilizada por el poeta "comprometido" con su época, con la problemática árabe general y con la guerra. Especial atención se dedicó al análisis de lo que ha supuesto, y supone para la poesía árabe la "invasión" cultural extranjera y cómo se ha producido su asimilación en la poesía árabe, que, a pesar de ello, sigue teniendo su propia y peculiar autenticidad, perpetuada hasta hiy desde hace tantos siglos.

"Si los debates literarios se pueden considerar el reflejo de la razón y la mente del Congreso, la recitación de poesía es el espejo de su alma y su corazón", comentó conversando conmigo uno de los poetas árabes participantes. Estas sesiones poéticas, que, al igual que las de crítica literaria duraban unas ocho horas diarias, brindaron la oportunidad de intervención a un sinfín de poetas, en su mayoría árabes. Los poemas recitados fueron de muy diversa indole: desde poesía amorosa a poesía de guerra, desde poemas de estructura tradicional, escritos siguiendo las pautas de la poesía clásica, a poemas de estilo occidental. Aunque la temática era libre, y por lo tanto diversa, predominaba en muchos de los poemas la constante referencia a la causa árabe, siendo tratados principalmente el problema palestino, el conflicto libanés y la guerra de Iraq. Dada la numerosísima asistencia - hubo más de mil intervenciones-, resulta difícil hacer una selección de nombres; es preciso, con todo, manifestar que asistieron varias generaciones de poetas y que la presencia de poetas jóvenes era notable. Entre los participantes, por nombrar algunos poetas, estuvieron: 'Abd al-Rahmān Maŷĩd al-Rubay'í, 'A Abd al-Razzāa 'Abd al-Wāhnid (4), 'Abd al-Wahhāb al-Bayātī, Āmāl al-Zahāwī, Hādī Yāa-

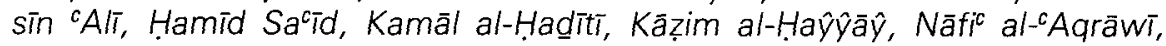

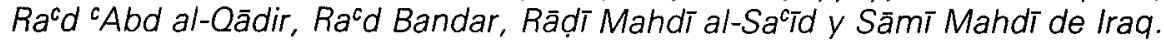

La amplia participación de poetas de otros países árabes hace también difícil seleccionar nombres; cabe señalar la presencia de Maḥmüd Darwiš (5)

(3) Muy interesantes resultaron las conferencias de 'Ali Abbās cAlwăn: "El carácter en la poesía de guerra», cuyo estudio se basaba en el comentario de poemas de Hamíd Sacid; la de Jaldūn al-Sama: "El símbolo histórico en la literatura de guerra», elaborada a partir del análisis de los poemas de Sămī Mahdi

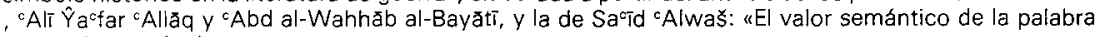
paz en la poesía de guerran.

(4) Durante la celebración, en 1986, del VII Mirbad fue anunciada la instauración del «Premio Saddăm de las Letras", considerado uno de los más importantes de la cultura árabe. El 12 de septiembre de 1987 se hizo pública su concesión; ha sido otorgado a seis personalidades de las Letras árabes: 1) Premio de poesía a 'Abd al-Razzăa 'Abd al-Wăhid (|raq); 2) Premio de marrativa a Tawfīq 'Yūsuf 'Awwăd (Líbano); 3 y 4) Premio de los estudios filológicos y lingüísticos (compartido) a Tamăm Hasan 'Umar y a Kamāl Muhammad Bašr (Egipto); 5) Premio de Historia de la Literatura a Husayn cAlwăn (Jordania), y 6) Premio de investigación y crítica literaria a Ạ̣mad Mațūb (Iraq). El premio es de 30.000 dólares.

(5) Este poeta, uno de los más célebres poetas árabes contemporáneos, clausuró el Festival el día 1 de diciembre con la recitación de poemas suyos en la sesión especial organizada en memoria de los mártires de la guerra, ya que el "Día del Caídon se celebra precisamente el 1 de diciembre. 
(palestino), Ahmad Sulaymān Ahmad (sirio), Nihād al-Hāyik (libanesa), Jalīfa al-Wiqyān (kuwaytí), Muhammad Jayr (sudanés) y Sacd Darwī̌ (egipcio).

A la nueva y más joven generación de poetas, cuyas intervenciones fueron acogidas con mucho éxito, pertenecen Muhammad al-Qaysī (6) (palestino), Muhammad al-Taubi (marroquí), Muhammad al Sagīr Awlād Ahmad (tunecino), al-Habid al-Zuwaydi (jordano) y el jovencísimo poeta de Mauritania ‘Abd Allāh Walad Būna.

No es mi intención dedicarme a hablar ahora sobre la poesía iraquí moderna; pero ya que presento una selección de poemas traducidos, sícreo conveniente apuntar algunos breves datos.

Se puede afirmar que hasta los últimos años del siglo XIX y primeros del $X X$, en su aplicación a temas de actualidad, la poesia árabe había seguido fiel a la imitación de la casida árabe clásica de métrica cuantitativa y monorrima. Esta tradición poética fue sustituida por una poesia de verso y metro libres por obra de los poetas sirio-libaneses que en los primeros años del siglo $X X$ se establecieron en los Estados Unidos. Entre los principales renovadores de la poesía árabe están el internacionalmente famoso Jalï Ŷubrān (m. 1931), Amìn al-Rịhānì (m. 1940), Mijā'î Nucayma (m. 1988), Ilyā Abū Māọi (m. 1957) y otros. Estos poetas, influidos por la poesía moderna de Occidente -fueron grandes admiradores de Walt Whitman, T. S. Eliot y Ezra Pound-, cambiaron los cánones estéticos y el contenido de la poesía árabe. La nueva tendencia fue aceptada y seguida con éxito por los escritores de todo el mundo árabe. La poesía iraqui también se vio afectada por la nueva tendencia creada por los poetas emigrados o en el exilio. En Iraq, la poesía ha tenido en lo que va de siglo un florecimiento importante, y dentro de las letras árabes la poesía iraquí ha jugado y juega un papel decisivo. Los dos primeros poetas del siglo XX, verdaderamente renovadores, son Macrüf al-Rușāff (m. 1945) y $\hat{Y}$ amīl Sidqĩ al-Zahāwì (m. 1936). A partir de ellos la creación poética iraquí inició un nuevo curso y han sido otros dos poetas iraquíes los que de manera más notoria han contribuido al florecimiento de la poesía árabe contemporánea: la poetisa Nāzik al-Malā'ika y Badr Sākir al-Sayyāb (m. 1964). Otro importante poeta cuyas obras siguen teniendo gran aceptación en el mundo árabe, y también en Occidente, en 'Abd al-Wahhäb al-Bayātī, poeta muy conocido en España, puesto que lleva varios años residiendo en nuestro país, y cuya poesía se ha traducido a varias lenguas.

Según la crítica, la mayor aportación de los poetas citados es que con ellos la poesía árabe se ha convertido en una poesía dirigida al hombre, al mundo entero. Es este tipo de poesía, en metro libre, el que presento en esta ocasión (7).

16) Premio Ibn Jaŷāa 1984 del Instituto Hispano-Árabe de Cultura (Madrid) por su diwān Manāzil fi-l-Ufq. (Jamsūna Qașidat al-Hubb) (Casas en el Horizonte. Cincuenta Poemas de Amor).

(7) De todas formas sigue existiendo un tipo de poesía de corte clásico, muy en boga y que incluso la nueva generación de poetas adopta en ocasiones, ya que constituye un arte que todo buen poeta debe cono- 
C 
Mi asistencia como arabista invitada a este VIII Festival de Poesía y el hecho de haber residido tres años en Bagdad ha sido lo que me ha llevado a escribir estas notas. Me gustaría ofrecer este pequeño trabajo como un modesto homenaje a Iraq, y en especial a todos los que han muerto en la guerra, algunos amigos mios. Su recuerdo permanece y ha constituido la inspiración de muchos poemas del VIII Mirbad.

A continuación presento una selección de poemas que he traducido del árabe. La revista literaria iraquí al-Aqlām (8) ha dedicado un volumen especial ( $n .^{\circ} \mathrm{s} 11$ y 12 ) a la poesía iraquí contemporánea, $y$ de este volumen he seleccionado todos los poemas excepto los dos del poeta Amŷad Muhmmad Sacid que pertenece a su dīwān al-Hișn al-Sarqi (9).

cer y ejercitar. Se ha dicho en numerosas ocasiones que a la poesía árabe le fue desde un principio mucho más difícil que a la prosa «liberarse» de toda tradición clásica. Talvez la voluntad de no renunciar a ella jugó un papel decisivo para que esta tradición se haya conservado. Muestra de su vitalidad ha sido este VIII Mirbad, en el que la mitad de los poemas eran auténticas casidas clásicas.

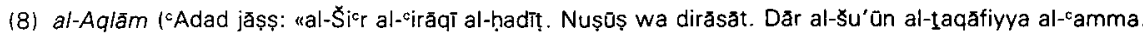
Wizårat al Taqåła wa-l-|clăm. Bagdad 1987), n. ${ }^{\circ} 11 / 12$. Se trata de una revista literaria publicada por el Ministerio de Cultura e Información de Iraq. Este volumen especial está dedicado a la poesía iraquí contemporánea.

(9) al-Hişn al-Šaraĩ (Dãr al Su'-un al-Taqāfiyya al-`Āmma. Bagdad 1987. El mismo día de la inauguración del Festival se inauguraba la feria Anual del Libro Iraquí. Se presentaban más de ochocientos títulos nuevos de literatura árabe. Además de otras muchas novedades de obras traducidas al árabe, llamaron la atención las traducciones al árabe de Hamlet y Otelo hechas por el escritor palestino-iraquí Ýabră lbrāîm Ŷabrã. 
CANTO A LA PATRIA

Sigue el rocio

sobre la superficie de las ramas, sigue el árbol

estando erguido,

sigue saliendo la luna,

y los ojos

Zlenan la tierra de amor.

En cada corazón se abren unos soles

$y$ siguen abiertas las ventanas de par en par

y siguen las calles repletas

y los soldados expectantes.

Siguen los hombres

escribiendo sus himnos

$y$ sus escritos

confortan las almas.

Todo permanece en calma

sin que padezca

ni una mota de polvo del Iraq.

(10) Poema de Amŷad Muhammad Sacĩd: Diwān al-Hișn al-Šarqĩ pp. 19-20. 


$$
\text { غنائية للوطن }
$$

ما يزال الندي'

فوق وجه الغني الغنون

ما يزال الشجر

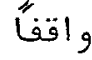

و و القمر

Lelb

و, البعيونْ

تملاء الارّض حُ"

و تفتح ,في كل قلب؛ شموسا" الارض

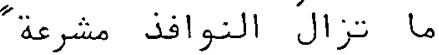

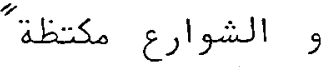

و الجنوز

سا هر ين

ما يز ال" "البشر

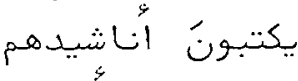

و أشاطيرهم:

يمنحون النفوسا

كل شيء تيهون

غير إن تشئكي

ذرة

من تراب العراقْ 


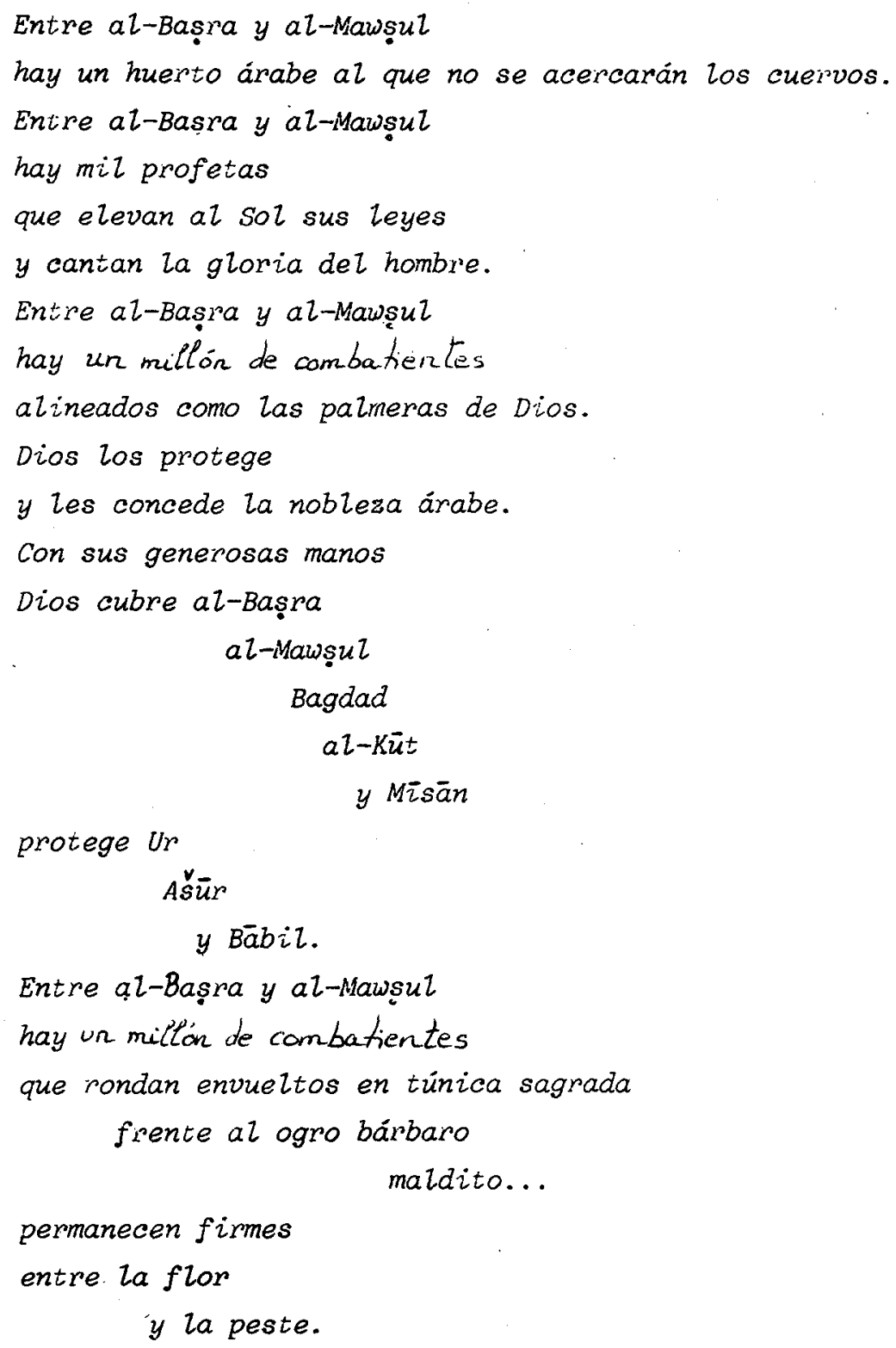

111) Poema de Amŷad Muḥammad Sacîd: Dîwăn cit. nota precedente, pp. 67-68. 
دعائية للعرات

ما بينَ البمرة و المومل حقل عربي لا تقربه الغرة الغوبان ما بين البصرة و و الموصل الفو نبي يرفع للشمس شرائعه'

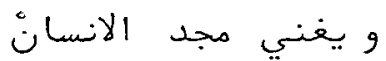

ما بين البصرة و المومل مجن لاندي مليونِ مقاتل

يصطفون كنخل الله.
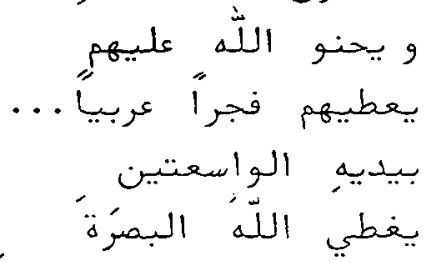

و الموصل

بغداد

الكوت

و ميسان

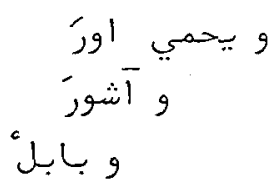

ما بين البصرة و الموصل مليون مقاتل

يلتفوّن كثوبِ قدسيّ

في وجه الغنول الوحشي قدئ

الملعون

يقفون

ما بين الوردة

و الطاعونْ

215 
Una hemorragia se extiende

desde el corazón al horizonte,

desde el pájaro al disparo,

desde el dia a la noche.

Un vaso lleno de óxido y polvo,

un sopor que arrebata la cabeza,

una ceguera que secuestra el ojo,

la fisura hacia el no limite,

el pasadizo hacia el no pais,

el viaje hacia el no asentamiento;

por al-Andalus el corazón se enternece $y$ despierta,

por la ausente, una flor de piedra,

casidas de ILuvia;

tiene labio y almonada,

tiene cuelto y lecho.

\section{2}

Los puentes del retorno son gacelas de fiebre,

laderas de lodo y sal;

la imagen del santuario es de humo,

los ojos del viento apuntan hacia ella,

las leyendas de la quimera y los cuentos de la noche

se ausentan de su memoria;

alıá..., una nube,

barro,

destelzo,

zumbido,

sequia,

primavera;

alzá..., tú.

(12) Poema de 'Abd al-Rahnmān Maŷĩ al-Rubaỵĩ̃: al-Aqlăm pp. 40-41. 
اختشاق

$$
\begin{aligned}
& \text { نزف يطول } \\
& \text { من القلب الئ الأفق }
\end{aligned}
$$

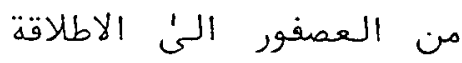

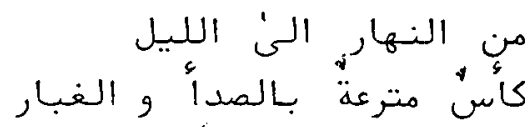

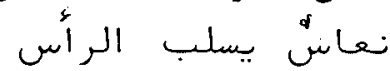

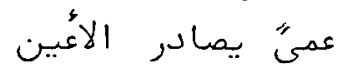

$$
\begin{aligned}
& \text { الفجوة الني اللامدى الاعين }
\end{aligned}
$$

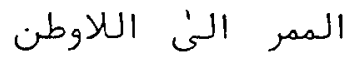

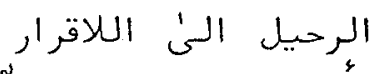

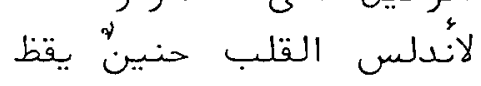

$$
\begin{aligned}
& \text { للغائبة زهرة لائر من حجر }
\end{aligned}
$$

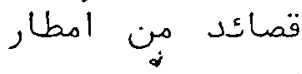

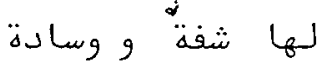

$$
\begin{aligned}
& \text { لها لها العنق و السربير وسالدة } \\
& r
\end{aligned}
$$

قناطر" الرجوع غزالات من من الحمّى

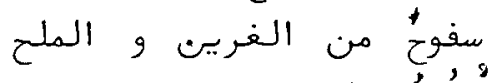

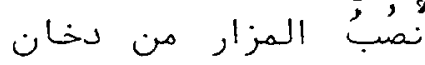

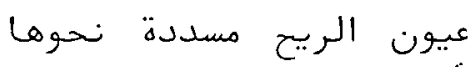

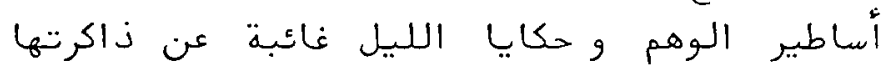
ثمة غيمة الطاطير طين ع ش ازيز قحط 
Esta voz potence mia

no escancia los cactus del desierto:

a ese árbol estéril

Lo cubre la arena,

escondiéndose en él los escorpiones de la soledad, cercado por quien está alzi,

huyendo de quien está allí, en mis viñas, mis palmeras, mis ventanas, mi pasión, mi muerte.

Un viajero sin acompañante;

Lo abandonaron los palacios de azulejos,

Io habivaron los espejos de la derrota y de ta adulación; ocupado por su silencio, sofocado pos él, asesinado por él, ¿qué alegria disipa su melaneolia conduciéndole hasta alzi?

\section{5}

Lo avientan los aires de la tristeza, ¿cómo lo recogerá el rocio de la alegria?

6

Un cetro para la princesa del cearo,

ofrendas para esa que se refugia en la soledad y en los poemas. ¿Quién alcanza su trono montañés? 


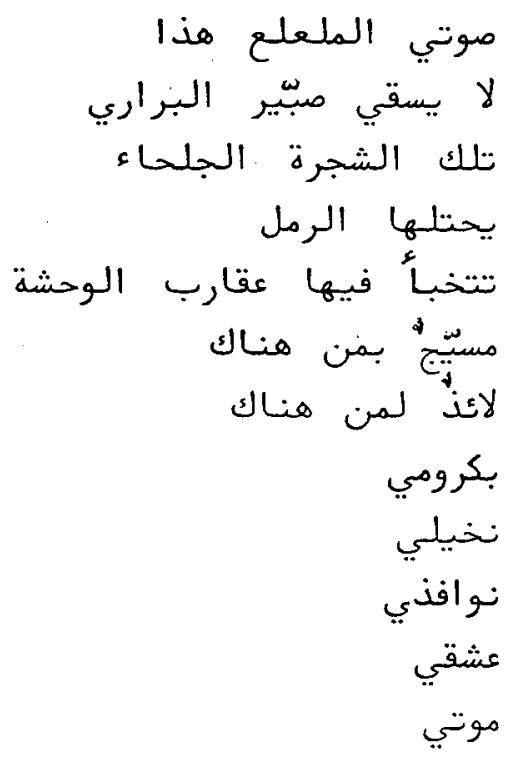

$\varepsilon$

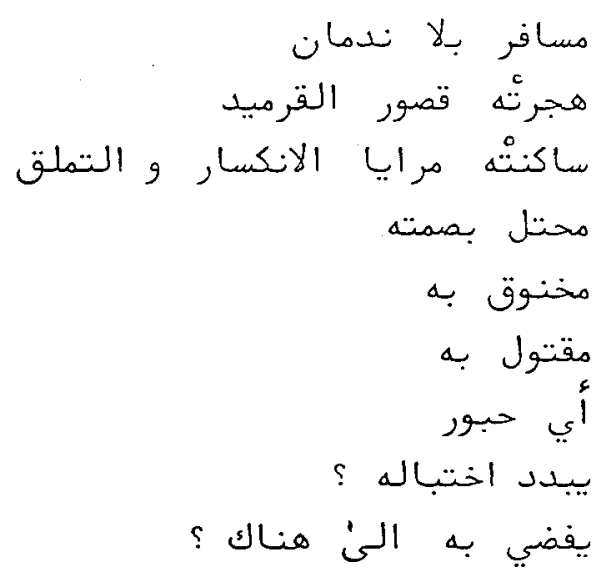

0

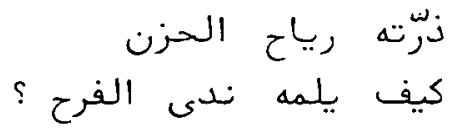

1

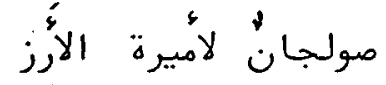

قرابين لتلك اللائنة بالوحدة ولأرز الأشعار من يصل عرشها الجبلي ؟ 
¿quién enciende el fuego en los braseros de nieve? ¿quién anuncia la boda durante las estaciones del polvo?

\section{7}

Palomas, ramas, pastores, amintes;

amuletos, párrocos,

santos, beatos, anacoretas, niños, estrellas, alheña y promesa de un abrazo.

8

¿Dónde están las velas de los rios de verano? ¿dónde están los vientos de los barcos que arriban?

9

Un saludo que anuncian los jardines del dia; para la princesa del cedro, me armo con el milagro, proclamo la repüblica del céfiro, me embriago como el águila en su cielo, como un pez que se mece en la ola, Zuego, la sigo. 
من يشعل النـار في مواقد الثلج ؟ من يعلن العرس في فمول الغبار ؟ في اقدل v

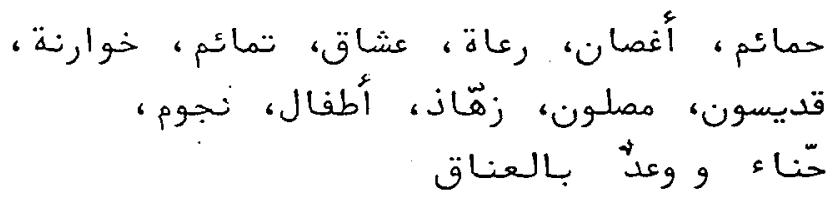
$\wedge$.

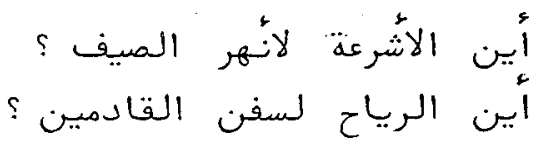

9

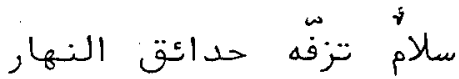

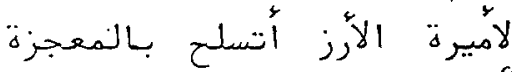

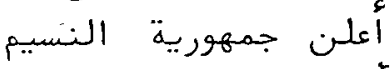
أنتشي مثل نسر فهورة في سمائه

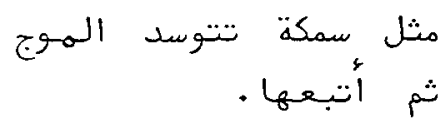




\section{$A L-B A S R A$}

Ella, como es costumbre de sus gentes sencillas, cometia la heroicidad y el sacrificio, destilaba la Historia en milagro, en signos de victoria, y con su semblante árabe, en todas las épocas - la ciudad de los poetas y de los sabiosresistió a los invasores. $y$ con el árbol más noble, la palmera, $y$ con su estero, 14 era para los caidos en su ascensión al cielo el alimento del paraiso. La poesia era el secreto de su juventud y la heroicidad de su gente el pilar.

Los bucles de tus cabellos en los espejos del mar:

una ventana y un pájaro que vuela, $y$ dos rosas, y yo soy el viajero en el tiempo $y$ en el espacio y en los exizios léxicos y métricos mi lenguaje brota con tu luz $y$ se convierte en los candiles de la ternura, florece, se convierte en moradas para los corazones..., se convierte el tiempo en un jardin. El mar es el espejo del jardin y del tiempo.

(13) Poema de 'Abd al-Wahhăb al-Bayătĩ; al-Aq/am p. 6. 


$$
\begin{aligned}
& \text { كاتت، كعادة أهلها البسطاء }
\end{aligned}
$$

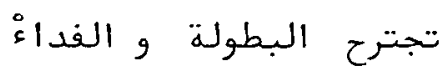

$$
\begin{aligned}
& \text { تستقطر التاريخ معجزة" لئولة } \\
& \text { وشارات ات انتصاز } \\
& \text { و بوجه8ا وسكال العربيّ } \\
& \text { في كل العصورِ }
\end{aligned}
$$

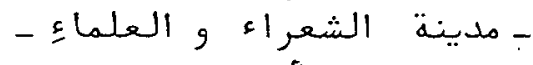

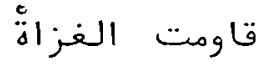

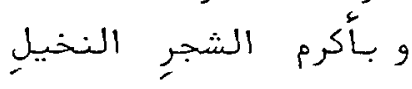

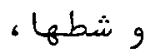

$$
\begin{aligned}
& \text { كانت الى الى الشهداء في في معراجهم } \\
& \text { الشعر سر شبادبها } \\
& \text { و بطولة البشر البناة } \\
& \text { خملات شعركٍ في مرايا } \\
& \text { البحر : } \\
& \text { نافذة و عصفورٌ ليطير } \\
& \text { و وردتان }
\end{aligned}
$$

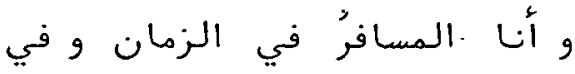

$$
\begin{aligned}
& \text { المككان } \\
& \text { و في منافي الابججدية و العروضن } \\
& \text { لغتي بضوئك أورقت } \\
& \text { مارت قناديل المحبة } \\
& \text { اززهرت } \\
& \text { مارت منازل ازهرت للقلوب؟ }
\end{aligned}
$$

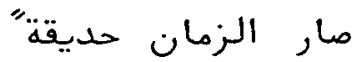

$$
\begin{aligned}
& \text { و البحر مرآة الحديقة و الزمانْ . }
\end{aligned}
$$


Mi pais se vestia con la túnica de la primavera. Detuve mi montura

$y$ dije:

¿por cuánto vende, mi Sultana,

esta luz azul, rosada,

esta túnica,

estos jazmines?

Me respondió riéndose...

"Por todas las casidas

de los poetas,

pero no los venderé".

(14) Saț al-cArab. 


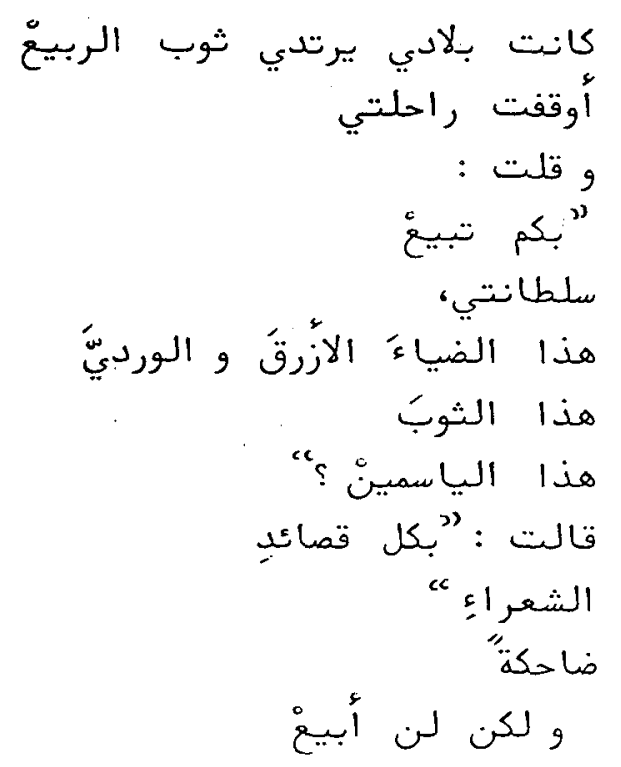

225 


\section{RERLEXION 15}

¿quién sabe

qué le confiesa la estrella al manantial

desde el atardecer hasta el alba?

¿quién sabe

qué le susurra el pájaro

a las ramas y a las copas de los árboles del bosque

durante la estación del invierno?

¿Quién sabe

cuántas penas sufre el poeta cuando busca

los riachuelos y los manantiales

y cuántas veces agoniza

para que un ave encienda una de sus palabras?

Yo también, cuando expiro mi último aliento:

cuánto rescoldo dorado permanecerá en mi corazón,

y sobre cuántos mundos, dentro de mi, caerá la destrucción?

(15) Poema en lengua curda del poeta Lațif Hahlmaht. (Traducción al árabe de Benjamín Johanna Daniel): al-Aqlăm p. 63. 
تساؤول

$$
\begin{aligned}
& \text { مَنْ ذا الذي يعلم } \\
& \text { ها الذي تفضي به النهي النجة للينبوع ؟ } \\
& \text { من المساء و حتى الذئ المباح ؟ } \\
& \text { من ذا الذي يدري الذي التين }
\end{aligned}
$$

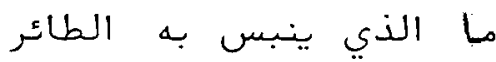

$$
\begin{aligned}
& \text { لا غصان و الذي افرع شجر الغاب الغاتر }
\end{aligned}
$$

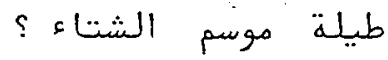

$$
\begin{aligned}
& \text { من ذا الذي يعلم: الذئم: }
\end{aligned}
$$

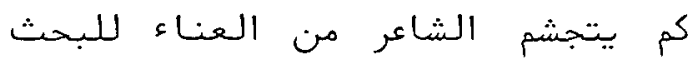

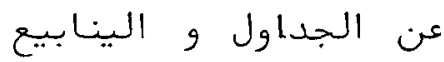

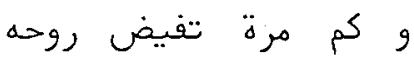

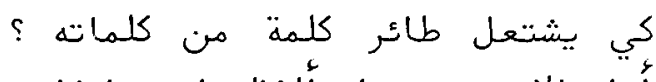

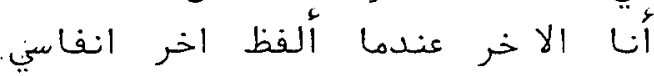

$$
\begin{aligned}
& \text { كم جذوة ذهبية ستظل في قلبي } \\
& \text { و كم عالَم سيحل به الخرابة في رئر رأسي ؟ }
\end{aligned}
$$




\section{EL $S O L^{16}$}

!Oh!...! Oh Sol remoto!

Estoy loco de arnor por ti

y no tengo nada más que la poesia.

Tenderé mis poemas

en las ramas y las copas de los robles de Küwistān',

en los labios de los niños de mi tierra,

y me encaminaré hacia ti.

(16) Poema de Lațif Hahlmaht: al-Aqlăm p. 63

(17) Son las zonas montañosas muy frías. 
الشمس

$$
\begin{aligned}
& \text { آه .. ايتها الشمس القصية }
\end{aligned}
$$

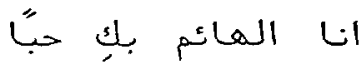

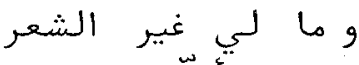

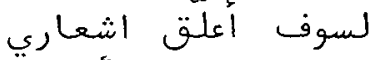

$$
\begin{aligned}
& \text { علن اغصان و أفرع سنديانات كويستان }
\end{aligned}
$$

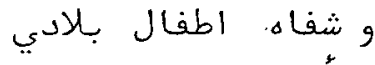

$$
\begin{aligned}
& \text { و أيمم شطرك اطنطا. }
\end{aligned}
$$


Le dije un to-

que los poetas descubrieron la Historia.

Le dije un dia que yo soy un "poeta":

se levanta si se le mata, sacrifica la vida si se le ignora,

no se le perdona que la oscuridad se pose sobre su horizonte

y que eleve un espacio entre dos heridas...

Aglomeraba la luz en mis ojos

y una vela entresacaba de mis ojos

una Historia de mentiras.

Al principio el juego era

que yo engañase a las velas,

que pretendiese un deseo

y que me tenaiera sobre la "virtua" de la humizaad.

$Y$ de repente

se enfria el ardor del poema,

se abate el cadáver de la letra

en la horca de las palabras.

I su mano dibuja, donde el poema parece una mentira, un interrogante.

(18) Poema de Mundir al-Ŷabbūrī: al-Aqlām pp. 68-70. 
علامة استفهام

$$
\begin{aligned}
& \text { أخبرتُها يومًا }
\end{aligned}
$$

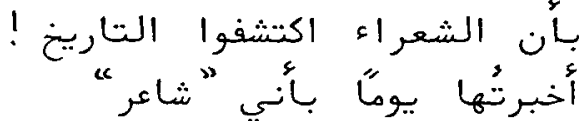

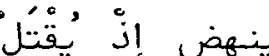

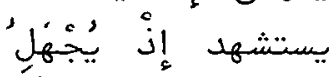

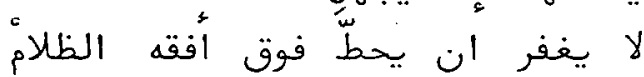

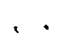

و يعتلي مسافة ما بين جرحين

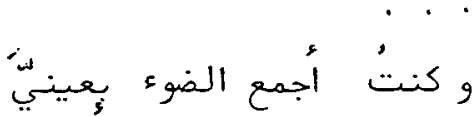

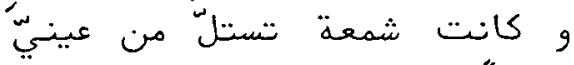

تاريخا من الكن

ابتداء" كانت اللعبة أنع

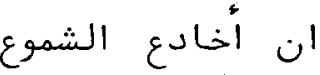

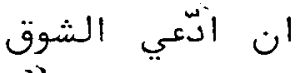

و استلقي على "فضيلة "فئي الخشوع

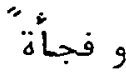

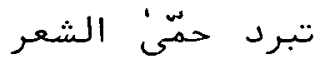

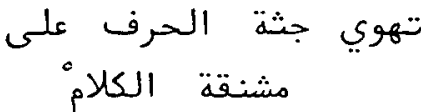

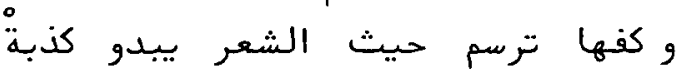

علامة استفهام

231 


\section{NOCTURNO $1^{19}$}

Tal vez huyo de ti, de mi; huyo de este mundo, me sumerjo en la escena de una pelicula en un libro, en el silencio de la calle, en el juego del viento; pero la noche me persigue, y la noche continua persiguiéndome, y la cinta del silencio me envuelve: algo se mueve en la oscuridad, un tic-tac se balancea sobre el muro, un agua gotea..., gotea..., gotea...

Un espejo brilla en las profundidades del fuego; de lo alto de la repisa llega un diálogo, la voz del pasado..., la voz del futuro; en ese instante no hay presente, todo se mueve en el futuro.

(19) Poema de la poetisa Mayy Muẓaffar: al-Aqlăm p. 73. 


\section{ليليات}

$$
\begin{aligned}
& \text { قد أهرب منك و مني .... أهرب من هذا العالم } \\
& \text { بكتابْ }
\end{aligned}
$$

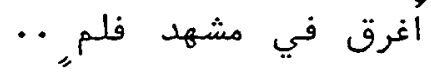

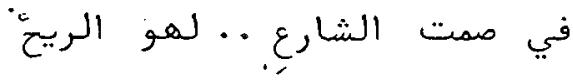

$$
\begin{aligned}
& \text { بل يبقى الليل يتابعني } \\
& \text { لكنّة الليلَ يتابعني . } \\
& \text { و شريط الصمت يكمني : }
\end{aligned}
$$

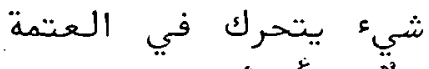

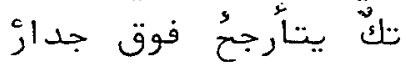

$$
\begin{aligned}
& \text { ماء يقطر . . يقطر . . . يقطر } \\
& \text { مرآة تلمع في أعماق النارْ }
\end{aligned}
$$

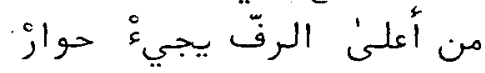

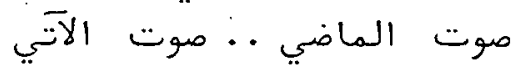

$$
\begin{aligned}
& \text { لا حاضر في هذه اللهي هونة } \\
& \text { كل" يتحرك في الاتتي }
\end{aligned}
$$




\section{¿ POR QUE ? 20}

Te reiste de mi, y no sabias con qué susto, y el corazón tembzoroso, robé la manzana

del jardin de los vecinos.

Corrió el jardinero, deprisa, tras de mi, vio la manzana en tu mano, me miró enfadado.

Se cayó la manzana de tu mano, esa manzana en la que

$$
\begin{aligned}
& \text { hincaste tus dientes, } \\
& \text { se cayó en el polvo. }
\end{aligned}
$$

Y hasta ahora, después de años, existe en mi oido un zumbido tenue, tenue... tu partida...

La pérdida de nuestra manzana... aumentan mis sufrimientos.

Sigo pensando, me sumerjo en el oleaje de la memoria. Me pregunto ¿por qué?, ¿por qué no tenemos un manzano en el jardin de nuestra pequeña casa? ¿por qué se nos priva de... manzanas?

(20) Poema de Năfi ${ }^{c c}$ Aqrăwī: al-Aqlām p. 75. 
لمازا ؟

$$
\begin{aligned}
& \text { لقت ضحكت عليّ .. و لم تملنّ. }
\end{aligned}
$$

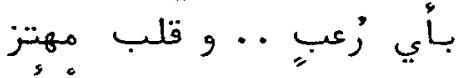

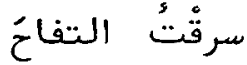

$$
\begin{aligned}
& \text { من حديقة الجيران } \\
& \text { ركض البستاني" ... بسرعة ورائي } \\
& \text { شاهد التفاح في يدك .. }
\end{aligned}
$$

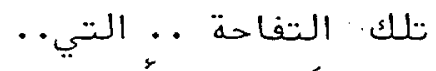

$$
\begin{aligned}
& \text { وقعت التفاحة من يدك }
\end{aligned}
$$

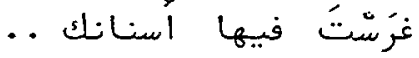

$$
\begin{aligned}
& \text { وقعت في التراب فئ ... }
\end{aligned}
$$

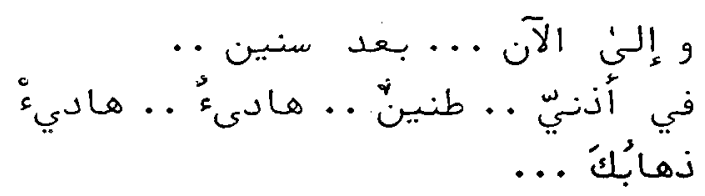

$$
\text { فقدان' تفاحتيا : }
$$$$
\text { •أظل }
$$

$$
\begin{aligned}
& \text { اغرق في تلاطم زاكرتي } \\
& \text { أقول ـ لمانا . . ؟ لمازا . . ؟ }
\end{aligned}
$$

لا نملك في حديقة بيتتا الصغير تناحاً .. ؟

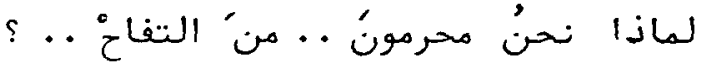




\section{TRAVESTA $^{21}$}

Como nubes que se desvanecen en el viento pasamos con los dias en su travesia, desde una ola errante a una costa herida. Como una bruma en la espaciosa lejania pasa con nosotros una nave desconocida, desde un puerto truncado a uno en el viento. Como una probabilidad lóbrega es nuestra travesia: nos sumergimos en su oscuridad... para descansar. 


$$
\text { عبور }
$$

$$
\begin{aligned}
& \text { مثل سحاب ساقط في الريخ } \\
& \text { تمضي مع الايام في عبورنا } \\
& \text { من موجة تائهة لشاطيء مبريح } \\
& \text { مثل ضباب في من الدمدى الفسيخ }
\end{aligned}
$$

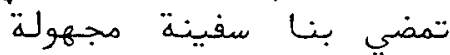

$$
\begin{aligned}
& \text { من مرفا منكسر لمرفا في الريخ }
\end{aligned}
$$

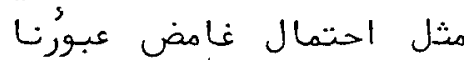

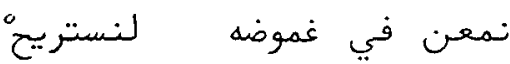




\section{MALA JUGADA}

:Cuántas veces ha Zlamado un viento a nuestra puerta haciéndonos creer que era él el que venia! : ; y cuando me levantaba para abrir la puerta, me decia a mi mismo: !Cuántas veces nos arropamos en nuestra ilusión! ¿Qué sucedería si él

se equivocara de camino una vez y viniera? ¿Cómo, entonces, concluiria el invierno? 


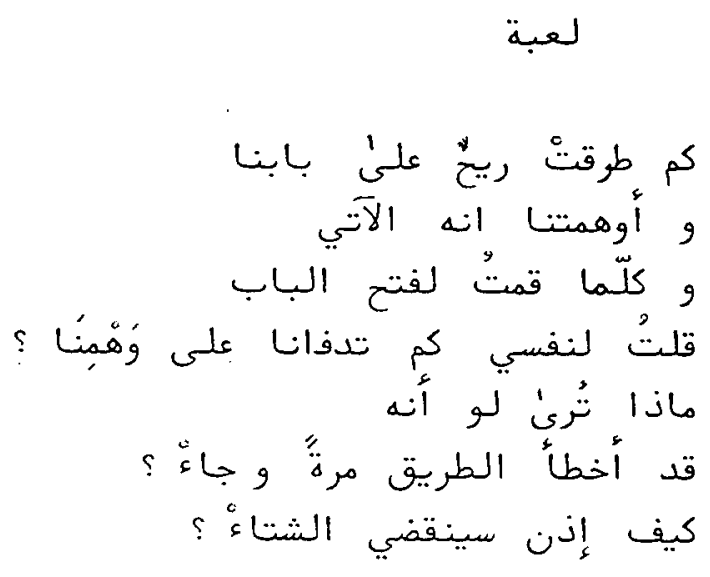

